\title{
Can Fluoroquinolones Cause Peripheral Neuropathy? The Drugs Manufacturers Say "Yes"
}

\author{
R Jason Richards* \\ Partner Aylstock Witkin Kreis and Overholtz Pensacola, USA
}

Submission: September 12, 2017; Published: October 26, 2017

*Corresponding author: R Jason Richards, Partner Aylstock Witkin Kreis and Overholtz Pensacola, Florida, USA, Email: jrichards@awkolaw.com

\section{Letter to Editor}

Over the years there has been considerable disagreement in the medical community about whether Fluoroquinolones (FQs) are associated with peripheral neuropathy. By 2004, however, all FQ labels reflected that peripheral neuropathies have been reported with the use of FQs [1]. And by 2013, both FQ manufactures and the FDA were in agreement that peripheral neuropathy was associated with $\mathrm{FQs}$ and agreed to update the information in the Warnings and Precautions section of the labels and the patient Medication Guide accordingly.

In 2016, the FDA issued yet another class-wide label change, revising the warnings for peripheral neuropathies to a boxed warning, the FDAs strongest warning. Following these recent class-wide labeling changes, the issue of whether there is an association between FQs and peripheral neuropathy is or at least should be settled.

It was therefore surprising to read an article published in the March 2017 issue of the Journal asserting that no "true association" between FQs and peripheral neuropathy has been "substantiated"[2]. The article, titled "Do Fluoroquinolones Cause Neuropathy", argues that the hundreds of reported adverse events concerning peripheral neuropathy received through the Adverse Event Reporting System (AERS) and analyzed by the FDA reveal only that "while an association between Fluoroquinolones and peripheral neuropathy is possible based on the data, a true association and the incidence of peripheral neuropathy in patients taking these antibiotics cannot be substantiated". The article goes on to state that "coincidentally, the number of reported peripheral neuropathy in association with Fluoroquinolones parallel to the launch of related lawsuits." The article then casts doubt on various published case reports and larger studies which find that such an association does in fact exist. In the end, the author concludes that "the accumulated data over years suggest a possible but not definite association between Fluoroquinolone use and peripheral neuropathy. Prospective studies are required to further establish such association." However, the validity of the author's comments regarding the lack of a true association between $\mathrm{FQs}$ and peripheral neuropathy are highly questionable in light of the available, objective evidence.

First, the claim that there is no "true association" between FQs and the incidence of peripheral neuropathy was not lost on the reader. As a lawyer representing FQ clients, I recognize this phrase as a term of art. Indeed, this phrase-true association-has special significance within the medical and legal communities. Under Sir Austin Bradford-Hill's causation analysis-the methodology used by many scientists in a court of law to extrapolate from "association" to "causation"-arguably requires that there be an "observed association" before passing to a verdict of causation [3]. In other words, absent a true association, there can be no reliable scientific opinion supporting causality that drug X caused injury Y.

Moreover, in many instances the author's criticisms of the case reports and studies appear to conflict with the conclusions reached by the study authors themselves. For instance, Karlman et al. [2] reviewed 40 patients treated with ciprofloxacin for acute or chronic osteomyelitis (38) and acute arthritis (2) [4]. The study identified 9 patients with adverse experiences. Of these 9 patients, the study authors reported one case of "peripheral par aesthesia" (a form of peripheral nerve damage) which they found was "probably related" to ciprofloxacin treatment. Paraesthesia is a well-established symptom of peripheral neuropathy.

Auon et al. presented a case report of objective evidence of axonal neuropathy following FQ exposure [5]. The study authors concluded there was an association between the use of pefloxacin, ofloxacin and ciprofloxacin and peripheral neuropathy in the patient. This conclusion was supported by the numerous positive dechallenges and rechallenges of the FQs in the patient. A positive recalling makes causality with FQs in this case report highly probable.

In 1996, Hedenmalm et al. [3] reported the results from a review of 37 patients treated with FQs [6]. Of those, $81 \%$ experienced parenthesis, 51\% experienced numbness, $27 \%$ 


\section{Open Access Journal of Neurology \& Neurosurgery}

experienced pain and 11\% experienced muscle weakness. The highest incidence of reported symptoms occurred during the first weeks of treatment, indicating rapid onset. The duration of symptoms in cases where information was provided varied from a few hours to over a year, indicating permanency in some patients. Good temporal relationship and positive dechallenge evidence existed in the majority of cases.

In concluding that no "true association" exists, the author also omits any discussion of or reference to other significant findings from published medical literature. For example, a 1990 study by Chan et al. reviewed 27 patients treated with the FQ Peflox for urinary tract infections [7]. One patient developed peripheral neuropathy that resolved 4 weeks after discontinuation. The authors of the case report concluded that "its relation to the use of pefloxacin was indisputable, since it recurred on re-introduction of the drug." More recently, an epidemiologic study published in the August 2014 online edition of Neurology provided additional quantitative support for the association between FQs and peripheral neuropathy [8]. The study compared 6,226 cases of peripheral neuropathy among men ages 48-80 to 24,904 controls and determined that those on FQs were at a statistically significant higher risk of developing peripheral neuropathy (RR $=1.83,95 \%$ CI: 1.49-2.27), with current users having the highest risk of exposure ( $\mathrm{RR}=2.07,95 \% \mathrm{CI}: 1: 56-2.74)$.

The author's comments are also at odds with the FQ labeling. In August 2013, the FDA issued a class-wide label change for FQs that was agreed to by the FQ manufacturers. That change resulted in the inclusion of the following language in the products' labeling: "Peripheral Neuropathies: Patients should be informed that peripheral neuropathy has been associated with Fluoroquinolones use" [9]. The label does not say that peripheral neuropathy "has been reported" with FQ use. The label does not say peripheral neuropathies "may be associated" with FQs. It says peripheral neuropathy "has been associated" with FQs. The patient Medication Guide was likewise amended in 2013 to reflect that peripheral neuropathy "can happen in people taking Fluoroquinolones" [10].

In July 2016, the FDA once again instituted a class-wide labeling change for FQs. This change resulted in a black boxed warning for peripheral neuropathy, the FDAs strongest warning. This updated labeling did not alter the 2013 language acknowledging the existence of the association between FQs and peripheral neuropathy. It simply reinforced, via the FDA's strongest warning, the previously recognized association. The 2016 black box labeling reads: FQs "have been associated with disabling and potentially irreversible serious adverse reactions that have occurred together, including: Peripheral neuropathy" [11]. Likewise, the patient Medication Guide still says that peripheral neuropathy "can happen in people taking Fluoroquinolones" [12].

Perhaps more importantly, not only have FQs been recognized by the manufacturers and FDA as "associated" with peripheral neuropathy, senior drug company officials have also acknowledged that the relationship is in fact "causal."

At the November 2015 FDA Adcom hearing to discuss the numerous risks associated with FQs, including peripheral neuropathy, a pharmaceutical industry spokesperson for the makers of the FQ drugs Cipro, Avalox and Levaquin acknowledged the following

FDA Advisory Committee Member: "does the sponsor disagree, number one, that quinolones because tendon ruptures, that quinolones cause severe arrhythmia, and then number three, that quinolones cause neuropathy?...

But it seems like we agree that there is a causal association with these three outcomes that we are discussing tendon ruptures, severe arrhythmia, and neuropathy. Yes?"

FQ Industry Representative: "Yes, We do agree” [13].

Once again, this information was publicly available over a year before the author's manuscript was published in March 2017.

The FQ manufacturer's unequivocal statements before the FDA, combined with the plain language set forth in the FQ labeling since 2013, belies any assertion that no "true association" between FQs and peripheral neuropathy exists. When the FQ drug manufacturers themselves admit that their drugs are associated with peripheral neuropathy-and even acknowledge a "causal association"-it would be prudent for medical professionals to accept these representations and avoid their use in patients with less serious bacterial infections unless they have no alternative treatment options. This guidance is consistent with the current recommendation by FDA for this class of antibiotics.

\section{Referances}

1. https://www.accessdata.fda.gov/drugsatfda_docs / label/2004/19537s053,054,20780s017,018lbl.pdf.

2. Amer AG (2017) Do Fluoroquinolones Cause Neuropathy? Open Access J Neurol Neurosurg 3(1): 555604.

3. Hill AB (1965) The environment and disease: association or causation. Proc R Soc Med 58: 295-300.

4. Karlman K (1988) Therapy of acute and chronic gram-negative osteomyelitis with ciprofloxacin. Report from a Swedish Study Group. J Antimicrob Chemother 22(2): 221-228.

5. Aoun M, Jacquy C, Debusscher L, Bron D, Lehert M, et al. (1992) Peripheral neuropathy associated with fluoroquinolones. Lancet 340(8811): 127.

6. Hedenmalm K, Spigset O (1996) Peripheral sensory disturbances related to treatment of fluoroquinolones. J Antimicrob Chemother 37(4): 831-837.

7. Chan PC, Cheng IK, Chan MK, Wong WT (1990) Clinical experience with pefloxacin in patient with urinary tract infections. Br J Clin Pract 44(12): 564-567.

8. Etminan M, Brophy JM, Samii A (2014) Oral fluoroquinolone use and risk of peripheral neuropathy: a pharmacoepidemiologic study. Neurology 83(14): 1261-1263. 
9. https: / / www.accessdata.fda.gov/drugsatfda_docs / label/2013/019537s082,020780s040lbl.pdf

10.https: / / www.accessdata.fda.gov/drugsatfda_docs / label/2013/019537s082,020780s040lbl.pdf

11. https: / / www.accessdata.fda.gov/drugsatfda_docs / label/2016/019537s086lbl.pdf 12.https: / / www.accessdata.fda.gov/drugsatfda_docs / label/2016/019537s086lbl.pdf

13. (2015) Transcript, FDA's Joint Meeting of the Antimicrobial Drugs Advisory Committee and the Drug Safety and Risk Management Advisory Committee, pp. 197-198.

Your next submission with Juniper Publishers will reach you the below assets

- Quality Editorial service

- Swift Peer Review

- Reprints availability

- E-prints Service

- Manuscript Podcast for convenient understanding

- Global attainment for your research

- Manuscript accessibility in different formats ( Pdf, E-pub, Full Text, Audio)

- Unceasing customer service

Track the below URL for one-step submission https://juniperpublishers.com/online-submission.php 